\title{
ACTIVIDAD ENZIMATICA DE ALGUNAS SAPROLEGNIALES (OOMYCETES)
}

\author{
Mónica M. Steciow \\ Instituto de Botánica "'Spegazzini"', 53 № 477, \\ (1900). La Plata. Buenos Aires. Argentina
}

Palabras clave: Actividad enzimática, Saprolegmiales, materia orgánica

Key words: Enzymatic activity, Saprolegniales, organic matter.

RESUMEN

Se ensayó la actividad enzimática de algunas Saprolegniales (Achlya americana, A. apiculata, A. oligacantha, A. polyandra, A. prolifera, Dictyuchus monosporus, Isoachlya touroloides, Saprolegnia diclina y S. parasitica), en distintos medios sólidos. Estas especies fueron aisladas de materia orgánica flotante, en Rio Santiago YPdo. Ensenada, Provincia de Buenos Aires, Argentina), y se demostró que poseen actividad enzimática, in vitro, para la descomposición de pectina, celulosa, hemicelulosa, lignina y almidón.

\section{INTRODUCCION}

El término de "hongos acuáticos" se aplica a todos aquellos que normalmente completan su ciclo de vida. o desarrollan parte de él en el agua. siendo el medio en el que liberan o propagan las zoosporas y/o gametos (Cooke, 1961; Hudson, 1986).

Los hongos acuáticos zoospóricos, son vulgarmente conocidos como "mohos acuáticos". Están principalmente representados por los organismos cuya posición sistemática corresponde al Orden Saprolegniales (Clase Oomycetes)

La importancia de la zoospora de estos hongos residiría en su " poder" para seleccionar el sustrato sobre el cual se establece en virtud de su taxismo. Las zoosporas pueden responder positiva o negativamente a gradientes quimicos y pueden dirigirse hacia o fuera del sustrato

\section{SUMMARY}

IEnzymatic activity of some Saprolegniales (Oomycetes).]

The enzymatic activity of some Saprolegniales was assayed (Achlya americana, A. apiculata, A. oligacantha, A. polyandra, A. prolifera, Dictyuchus monosporus, Isoachlya toruloides, Saprolegnia diclina and $S$. parasitica), on different solid media. These species were isolated of organic matter floating in freshwater of Santiago river (Pdo. Ensenada, Prov. Buenos Aires, Argentina). Enzymatic activity in vitro was proved to the decomposition of pectin, cellulose, hemicellulose, lignin and starch.

según el caso. Entre los Chytridiomycetes y Oomycetes un número de especies exhiben un quimiotaxismo positivo en relación a sales minerales y aminoácidos bajo condiciones de laboratorio, produciéndose el enquistamiento sobre el sustrato (Fischer \& Werner, 1958; Carlile \& Machlis, 1965; Machlis, 1969).

En estudios realizados en el Río Santiago y afluentes (provincia de Buenos Aires) se han encontrado varias especies de Saprolegniales, las cuales crecen sobre materia orgánica flotante en descomposición (hojas, tallos, etc), provenientes de la vegetación costera (Steciow, 1988; Steciow, 1993).

El objetivo de este trabajo es demostrar la capacidad de algunos de estos hongos, de degradar determinados sustratos orgánicos naturales in vitro, tales como pectina (a pH 5 y a pH 7). celulosa, hemicelulosa, almidón y lignina, presentes en las células vegetales de los restos caídos en el agua del río. 


\section{MATERIALES Y METODOS}

Las especies ensayadas fueron: Achlya americania, $A$. apiculata, $A$. oligacantha, $A$. polyandra, $A$. prolifera, Dictyuchus monosporus, Isoachlya toruloides, Saprolegnia diclina y S. parasitica.

Para detectar la actividad pectinolítica se empleó el medio sólido detallado por Hankin \& Anagnostakis (1975). Este medio contiene: solución de sales minerales, $500 \mathrm{ml}$; extracto de levadura, $1 \mathrm{~g}$; agar $15 \mathrm{~g}$; pectina lavada (citrus o manzana), $5 \mathrm{~g}$; agua destilada, $500 \mathrm{ml}$.

La solución de sales minerales contiene por litro: $\left(\mathrm{NH}_{4}\right)_{2} \mathrm{SO}_{4}, 2 \mathrm{~g} ; \mathrm{KH}_{2} \mathrm{PO}_{4}, 4 \mathrm{~g} ; \mathrm{Na}_{2} \mathrm{HPO}_{4}, 6 \mathrm{~g} ; \mathrm{FeSO}_{4} .7 \mathrm{H}_{2} \mathrm{O}$, $0,2 \mathrm{~g} ; \mathrm{CaCl}_{2}, 1 \mathrm{mg} ; \mathrm{H}_{3} \mathrm{BO}_{3}, 10 \mathrm{ug} ; \mathrm{MnSO}_{4}, 10 \mathrm{ug} ; \mathrm{ZnSO}_{4}$. $70 \mathrm{ug} ; \mathrm{CuSO}_{4}, 50 \mathrm{ug} ; \mathrm{MoO}_{3}, 10 \mathrm{ug}$.

Este medio fue calibrado a $2 \mathrm{pH}$ diferentes: $\mathrm{pH} 5 \mathrm{y}$ $\mathrm{pH} 7$ para detectar 2 enzimas. El medio a pH 5 fue usado para detectar la actividad de poligalacturonasas (pectina depolimerasa, pectinasa). El medio a pH 7 fue usado para detectar la producción de pectato liasa (pectatotranseliminasa).

Para cada especie se utilizaron 2 placas de Petri para ambos $\mathrm{pH}$, inoculándose 3-4 colonias por placa, las que fueron incubadas a temperatura ambiente $\left(20^{\circ} \mathrm{C}\right)$ por 34 días. Cada ensayo se repitió 3 veces para todas las especies. Al cabo de este tiempo las placas fueron inundadas con una solución acuosa $1 \%$ de bromuro de hexadecil-trimetil-amonio. Este reactivo precipita la pectina intacta no degradada del medio y pone de manifiesto las zonas donde la pectina ha sido degradada, apareciendo como una zona clara, diáfana, alrededor de la colonia.

Para probar la actividad celulolítica de estos hongos se aplicó la técnica para "screening" de Theater \& Wood (1982). modificada.

El medio empleado para detectar la presencia de enzimas celulolíticas es el siguiente:

- solución convencional de sales (Czapek).

- celulosa: carboximetilcelulosa de alta viscosidad: $0.5 \%$

- agar: Bacto Difco: 1,5\%; (pH 5,5).

Se sembraron placas de Petri con 4 inóculos, las que fueron incubadas por 2-3 dias hasta que las colonias hayan crecido debidamente. Se realizaron 3 réplicas para cada especie ensayada. Las placas fueron luego inundadas con las siguientes soluciones en la secuencia $y$ tiempos indicados:

- rojo Congo: 0,1\%: 15 minutos.

- lavado con varios pasajes de $\mathrm{NaCl} 1 \mathrm{M}$

- virado con ácido acético 5\%: 30 segundos.

- lavado final con $\mathrm{NaCl} 1 \mathrm{M}$ : hasta 3 horas

El rojo Congo muestra una fuerte interacción o afinidad con los polisacáridos con uniones contiguas $B$ (1-4) de unidades D-glucopiranosil ( $\beta$-D glucanos), y una significativa interacción con $\beta-(1-3)$ D-glucanos, y ha provisto la base para ensayos usados para detectar colonias de microorganismos productores de celulasas. De tal modo este ensayo pone en evidencia la actividad de las $\beta$ D glucanasas usando un sustrato soluble agarizado (carboximetilcelulosa).

Por el agregado del rojo Congo, el medio adquiere el color propio del colorante. Luego de 15 minutos las placas de Petri fueron lavadas varias veces con una solución de $\mathrm{NaCl}, 1 \mathrm{M}$, visualizándose la hidrólisis como zonas decoloradas (halo diáfano) alrededor de la colonia y rodeando a las hifas. Estas últimas (frente del micelio) quedaron teñidas de rojo; las zonas de hidrólisis pudieron ser estabilizadas inundando las colonias con solución de ácido acético o ácido clorhídrico, $1 \mathrm{M}$, que cambióel color del medio (celulosa no degradada), a azul violáceo e inhibió la posterior actividad enzimática.

Para estimar la presencia o ausencia de enzimas capaces de degradar las hemicelulosas, se utilizó el siguiente medio: agar nutritivo (Difco), más $0,2 \%$ de xilano.

Luego de 3-4 días de incubación las placas de Petri fueron inundadas con una solución de iodo; los xilanos no degradados adquirieron una coloración oscura, mientras que la zona donde las hemicelulosas habían sido degradadas se manifestaron como un halo bien definido, claro. diáfano, alrededor de la colonia.

Para determinar la actividad amilolítica se empleó el medio detallado por Hankin \& Anagnostakis (1975). Este medio contiene agar nutritivo (Difco), más $0,2 \%$ de almidón soluble, $\mathrm{pH} 6$.

Luego de 4 dias de incubación a temperatura ambiente $\left(20^{\circ} \mathrm{C}\right)$, las placas fueron inundadas con una solución de Iodo. El almidón no degradado se tiñó inmediatamente de azul, mientras una zona amarilla alrededor de las colonias evidenció la degradación del almidón (zonas que aún sin el agregado de Iodo fueron igualmente visibles por su mayor transparencia)

El grado de degradación de la lignina por los hongos es dificultoso de precisar, ya que se trata de un polímero de estructura compleja, y cuyo desdoblamiento comprende desde la pérdida de un grupo metilo hasta la completa despolimerización de la molécula y ruptura del anillo bencénico. Sin embargo. es posible ensayar la desfenolización de la lignina en la vecindad de las colonias.

El medio sólido empleado es el siguiente: $\mathrm{NaNo}_{3}$. $2 \mathrm{~g} ; \mathrm{KCl} .0,5 \mathrm{~g} ; \mathrm{KH}_{2} \mathrm{SO}_{4}, 1 \mathrm{~g} ; \mathrm{MgSO}_{4} .7 \mathrm{H}_{2} \mathrm{O}, 0,5 \mathrm{~g} ; \mathrm{FeSO}_{4}$, $0,1 \mathrm{~g}$; extracto de levadura, $0,5 \mathrm{~g}$; sucrosa, $30 \mathrm{~g}$; agar, 15 $\mathrm{g}$; Indulina AT (lignina comercial), $0.5 \mathrm{~g}$ : agua destilada, 
1 litro (Fischer et al., 1983). Las placas fueron incubadas a temperatura ambiente, por el término de 4 días; al cabo de este período fueron inundadas con una mezcla de soluciones $1 \% \mathrm{FeCl}_{3}$ y $1 \% \mathrm{~K}_{3} \mathrm{Fe}(\mathrm{CN})_{6}$ en una proporción 1:1, dejándose en la oscuridad. La lignina no degradada adquirió el color azul-verdoso oscuro mientras la desfenolización de este producto se visualizó como una zona de color amarillo-verdoso alrededor y bajo las colonias.

Los resultados de la actividad enzimática de las especies ensayadas se expresaron, de acuerdo a las siguientes características:

$(+)$ : indica que el halo de la zona degradada o de hidrólisis es igual a la mitad del radio de la colonia o menor, en algunos casos coincide con el diámetro de la colonia (halo superpuesto con la colonia). Por lo general el aclaramiento de la zona degradada es poco intenso y reducido ("test" positivo débil).

$(++)$ : indica que el radio del halo de la zona de degradación es de la misma longitud que el radio de la colonia. Por lo general se trata de zonas bien definidas y de un aclaramiento intenso ("test" positivo).

$(+++)$ : indica que el radio del halo de la zona degradada es superior a lo expresado en $(++)$ : se trata de zonasbien definidas y de un aclaramiento intenso ("test" positivo fuerte).

( - ): indica falta de actividad ("test" negativo).

\section{RESULTADOS}

Los resultados obtenidos de la actividad enzimática de las especies ensayadas se detalla en Tabla 1.

Tabla 1

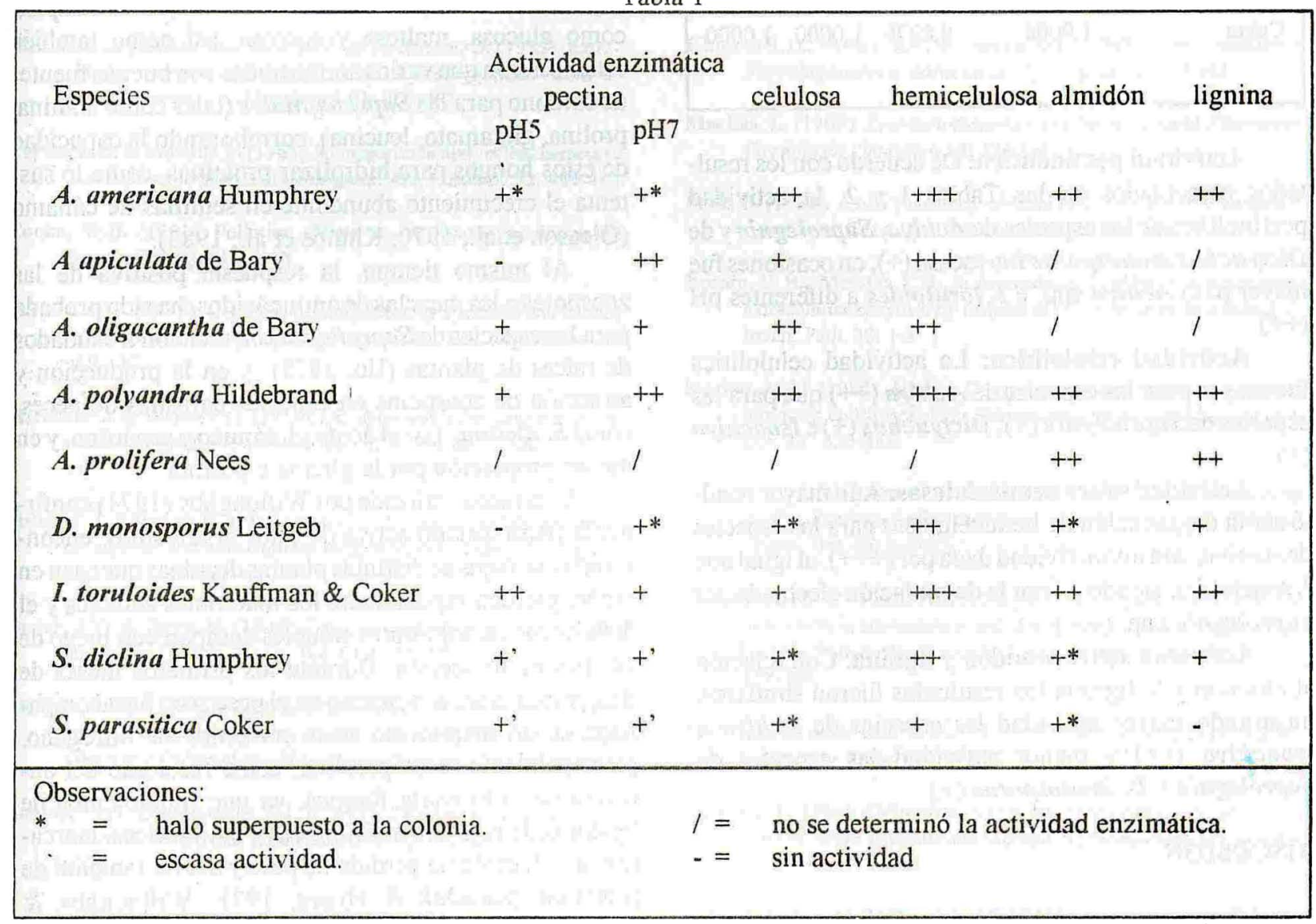

De las 8 especies que crecieron sobre la celulosa. hemicelulosa y pectina, se analizó la producción enzimática que fue expresada por la relación diámetro de la colonia/diámetro del halo (Foster \& Davis. 1949:
Rosato et al., 1981), de modo de poder estimar un análisis comparativo. en forma cuantitativa. de las enzimas producidas por las distintas especies (Tabla 2). 
Tabla 2

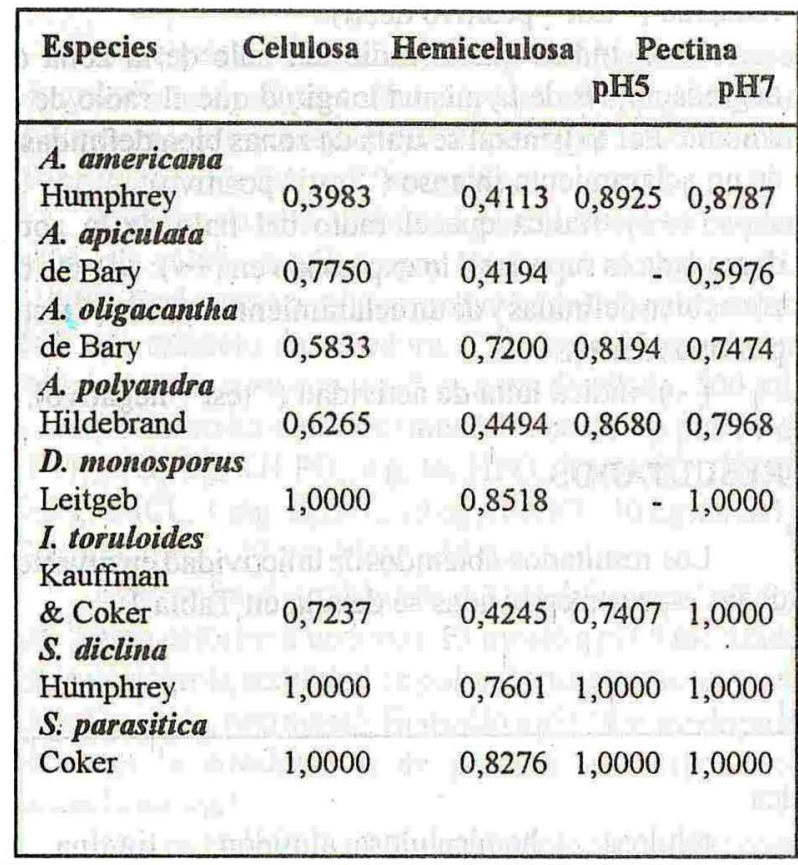

Actividad pectinolítica: De acuerdo con los resultados presentados en las Tablas 1 y 2 , la actividad pectinolítica de las especies de Achlya, Saprolegnia y de Dictyuchus monosporus fue escasa (+); en ocasiones fue mayor para Achlya spp. e I. toruloides a diferentes $\mathrm{pH}$ $(++)$

Actividad celulolítica: La actividad celulolítica fue mayor para las especies de $A c h l y a(++)$ que para las especies de Saprolegnia (+), Dictvuchus (+) e Isoachlya $(+)$.

Actividad sobre hemicelulosas: Aún mayor resultó ser la degradación de hemicelulosas para las especies $\operatorname{de} A$ chlya, con una actividad dada por $(+++)$, al igual que I. toruloides, siendo menor la degradación efectuada por Saprolegnia spp. $(++$ y +$)$.

Actividad sobre almidón y lignina: Con relación al almidón y la lignina los resultados fueron similares, mostrando mayor actividad las especies de Achlya e Isoachlya $(++)$ y menor actividad las especies de Saprolegnia y D. monosporus (+)

\section{DISCUSION}

Los organismos biótrofos y saprótrofos necesitan ciertas enzimas con la finalidad de utilizar sustratos nutritivos a expensas de los cuales viven. Estas enzimas degradativas producidas por los hongos son importantes en la infección del hospedador, el deterioro o descomposición de la materia orgánica (Unestam. 1966).
Estos hongos resultan ser abundantes sobre materia orgánica en descomposición encontrada en Río Santiago (Ensenada, Prov. Buenos Aires) y losensayos enzimáticos realizados ponen en evidencia que éstos juegan un importante papel en el recambio de nutrientes. Las especies utilizadas pertenecientes a los géneros Achlya, Dictyuchus, Isoachlya y Saprolegnia demuestran tener una producción de enzimas degradadoras de pectinas, celulosa, hemicelulosas, almidón y lignina. Unestam (1960), observó que una cepa de Saprolegnia sp y de Pythium sp no poseian enzimas celulolíticas detectables por los métodos empleados. Sin embargo, se han realizado experiencias que ponen a prueba la presencia de tales enzimas en el último género (Deacon, 1979; Park, 1980; Thompstone \& Dix, 1985) y la técnica empleada en las especies ensayadas dan resultados que demuestran la actividad celulolítica de estos hongos. Además Gleason et al. (1970), confirmaron la actividad amilolítica, y su capacidad de utilizar hidratos de carbono más simples, como glucosa, maltosa y sucrosa, así como también establecieron que varios aminoácidos son buenas fuentes de carbono para las Saprolegniales (tales como alanina, prolina, glutamato, leucina), corroborando la capacidad de estos hongos para hidrolizar proteinas, como lo sustenta el crecimiento abundante en semillas de cáñamo (Gleason et al., 1970; Khulbe et al., 1983).

Al mismo tiempo, la respuesta positiva de las zoosporas a las mezclas de aminoácidos, ha sido probada para las especies de Saprolegnia en relación a exudados de raices de plantas (Ho, 1975) y en la producción y atracción de zoosporas en especies parásitas de peces, como $S$. diclina, por el ácido glutámico y aspártico, y en menor proporción por la glicina y prolina.

El estudio realizado por Willoughby (1974) confirma la participación activa de estos organismos, encontrando que hojas de distintas plantas deciduas que caen en otoño, pierden rápidamente los materiales solubles y el $50 \%$ de los carbohidratos solubles desaparecen luego de 14 dias de inmersión. Durante los primeros meses de descomposición, el descenso en el peso seco fue acompañado en un incremento en el contenido de nitrógeno, principalmente como proteína, como resultado del aumento de la biomasa fúngica, ya que tratamientos de tejidos de la hoja con antifúngicos y antibióticos, marcaron la reducción de pérdida de peso y del incremento de proteínas (Kaushik \& Hynes, 1971; Willoughby \& Redhead, 1973). Debe destacarse la habilidad de estos hongos de acumular nitrógeno, principalmente de compuestos solubles en el agua, los que frecuentemente son deficitarios en este elemento, no dejando de lado la participación de otros organismos en este proceso.

Recientemente. Alberts et al. (1989), ponen en 
evidencia la actividad de enzimas extracelulares en medios sólidos para especies de Achlya, Saprolegnia y Aphanomyces, para las cuales se detectó actividad hemolítica, hidrólisis de caseína y presencia de desoxirribonucleasa, en distintas condiciones de laboratorio. Estas enzimas resultan particularmente importantes para aquellas especies parásitas de peces.

Las especies ensayadas en la presente contribución, fueron encontradas en el Río Santiago, sobre restos de tallos, hojas, etc., en forma periódica y/o constante; con el estudio enzimático realizado "in vitro", en medios sólidos, se comprobó la capacidad de estos hongos zoospóricos de degradar determinados sustratos orgánicos tales como pectina, celulosa, hemicelulosa, almidón y lignina, presentes en las células vegetales de los restos orgánicos caídos al agua del río, sobre los cuales se fijan las zoosporas y desarrolla el micelio.

\section{AGRADECIMIENTOS}

Deseo expresar mi agradecimiento a la Dra. A.M. Arambarri por sus consejos y la lectura crítica del manuscrito.

\section{REFERENCIAS}

Alberts, V.A., Khan, S.S., Lim, D.V. \& Te Strake, D. (1989). Extracellular enzyme activity of some Saprolengniales from a Florida estuary, Mycologia 81: 460-463.

Carlile, M.J. \& Machlis, L. (1965). A comparative study of the chemotaxis of the motile phases of Allomyces. Ann J. Botany 52: 484-486.

Cooke, W.B. (1961). Pollution effects on the fungus population of a stream. Ecology 42: 1-18.

Deacon, J.W. (1979). Cellulose decompositon by Pythism and its relevance to substrate-groups of fungi. Trans. Brit. Mycol. Soc. 72: $469-477$

Fischer, P.J. \& Werner, G. (1958). Die chemotaxis der Schwärmsporen von Wasserpilzen (Saprolegniaceen). Z. Physiol. Chem. 310: 6591

Fisher, P.J. \& Davey, R.A. \& Webster, J. (1983). Degradation of lignin by aquatic and aero-aquatic hyphonycetes. Trans. Brit. Mycol. Soc. $80: 166-168$.

Foster, J.V. \& Davis, H. (1949). Detection and occurrence of acid producing fungi. Bull. Torrey Bot. Club. 76: 174-176.

Gleason, F.H., Rudolph, C.R. \& Price, J.S. (1970). Growth of certain aquatic Oomycetes on amino acids. I. Saprolegnia, Achlya, Leptolegnia y Dictyuchus. Physiologia Plantarum 23: 513-516.

Hankin, L. \& Anagnostakis, S.L. (1975). The use of solid media for detection of enzyme production by fungi Mycologia $67: 597$ 607.

Ho, H..H. (1975). Observations on the behaviour of zoospores of a Saprolegnia species. Mycologia 67: 425-428.

Hudson, H. J. (1986). Fungal Biology. Contemporary, Edward Anold Ltd. London

Kaushik, N.K. \& Hynes, H.B.N. (1971). The fate of dead leaves that all in to streams. Archiv. für Hydrobiologia 68: 465-515.
Khulbe, R.D., Verma, B.L. \& Verma, D.L. (1983). A new medium of Saprolegniaceae. Bibliotheca Mycologica 91: 557-561.

Machlis, L. (1969). Zoospore chemotaxis in the watermold Allomyces. Physiologia Plantarum 22: 126-139.

Park, D. (1980). A two year study of number of cellulolytic Pythium in river water. Trans. Brit. Mycol. Soc. 74: 253-258.

Rosato, Y. B., Messias, C. L. \& Azevedo, J. L. (1981). Production of extracellular enzymes by isolates of Metarhizium anisopliae. J. Invert. Path. 38: 1-3

Steciow, M.M. (1988). Algunos Oomycetes de ambientes acuáticos de la provincia de Buenos Aires (Mastigomycotina). Bol Soc. Argent. Bot. $25: 333-346$

(1993). Presencia de Saprolegniales (Mastigomycotina) en Rio Santiago y afluentes (Prov. Bs. As., Argentina). Bol. Soc. Argent. Bot. (en prensa).

Theater, R. M. \& Wood, P.J. (1982). Use of Congo red-polysacharide interaction in enumeration and characterization of cellulolytic bacteria from the bovine rumen. Appl. Environ. Microbiol. 43 : 777.780 .

Thompstone, A. \& Dix, N. J. (1985). Cellulase activity in the Saprolegniaceae. Trans Brit. Mycol. Soc. $85: 361$.

Unestam, T. (1966). Chitinolytic. Cellulolytc and pectinolytic activity in vitro of some parasitic and saprophytic Oomycetes. Physiologia Plantarum 19: 15-30

Willoughby, L.G. \& Redhead, K. (1973). Observations on the utilization of soluble nitrogen by aquatic fungi in nature. Trans. Brit. Mycol. Soc. 60: 598-601.

(1974). Decomposition of litter in fresh water. In: Dickinson C.H. \& Pugh, G.J.F (Eds). Biology of Plant Litter decomposition. pp. 659-681. Academic Press. London \& New York. 